\title{
Kinetics of Hydrogen Absorption and Desorption in Titanium
}

\author{
S. Suwarno ${ }^{1, *}$, V.A. Yartys $\mathbf{s}^{2,3}$ \\ ${ }^{1}$ Department of Mechanical Engineering, Institut Teknologi Sepuluh Nopember, \\ Surabaya 60111, Indonesia \\ ${ }^{2}$ Department of Materials Science and Engineering, NTNU, NO-7491, Trondheim, Norway \\ 3Institute for Energy Technology, P.O. Box 40, NO-2027, Kjeller, Norway
}

Received: 21st November 2016; Revised: 20 $0^{\text {th }}$ March 2017; Accepted: $9^{\text {th }}$ April 2017;

Available online: 27th October 2017; Published regularly: December 2017

\section{Abstract}

Titanium is reactive toward hydrogen forming metal hydride which has a potential application in energy storage and conversion. Titanium hydride has been widely studied for hydrogen storage, thermal storage, and battery electrodes applications. A special interest is using titanium for hydrogen production in a hydrogen sorption-enhanced steam reforming of natural gas. In the present work, nonisothermal dehydrogenation kinetics of titanium hydride and kinetics of hydrogenation in gaseous flow at isothermal conditions were investigated. The hydrogen desorption was studied using temperature desorption spectroscopy (TDS) while the hydrogen absorption and desorption in gaseous flow were studied by temperature programmed desorption (TPD). The present work showed that the path of dehydrogenation of the $\mathrm{TiH}_{2}$ is $\delta \rightarrow \beta \rightarrow \alpha$ hydride phase with possible overlapping steps occurred. The fast hydrogen desorption rate observed at the TDS main peak temperature were correlated with the fast transformation of the $\delta-\mathrm{TiH}_{1.41}$ to $\beta-\mathrm{TiH}_{0.59}$. In the gaseous flow, hydrogen absorption and desorption were related to the transformation of $\beta-\mathrm{TiH}_{0.59} \Leftrightarrow \delta-\mathrm{TiH}_{1.41}$ with 2 wt.\% hydrogen reversible content. Copyright $\odot 2017$ BCREC Group. All rights reserved

Keywords: Titanium hydride; Hydrogen storage; TDS; Absorption kinetics; Desorption

How to Cite: Suwarno, S., Yartys, V.A. (2017). Kinetics of Hydrogen Absorption and Desorption in Titanium. Bulletin of Chemical Reaction Engineering \& Catalysis, 12 (3): 312-317

(doi:10.9767/bcrec.12.3.810.312-317)

Permalink/DOI: https://doi.org/10.9767/bcrec.12.3.810.312-317

\section{Introduction}

The use of sustainable and renewable energy is inevitable to reduce $\mathrm{CO}_{2}$ emission. The development of efficiently and environmentally conscience technology is a prerequisite for energy sustainability. The renewable energy sources are intermittent and the use of storage technology is necessary to drive their widespread used. Nevertheless, hydrogen and elec-

* Corresponding Author.

E-mail: warno@me.its.ac.id (Suwarno, S.)

Telp.: +62-31-5946230; Fax.: +62-31-5922941 tricity are considered the two most promising energy vectors. The well-known chemical energy storage devices are battery and hydrogen storage and one of the potential elements to be used in the energy storage device is titanium since it can be used for electrodes in batteries [1-3], and also for hydrogen storage materials. Titanium hydride has been found in some technical applications, namely aluminium foaming agent, production of high-performance $\mathrm{Ti}$ alloys by a thermo-hydrogen process. Nevertheless, a hydride material is searched to be used in enhanced hydrogen production concept so-called 
hydrogen sorption enhanced reactions (HSER). In the HSER concept, hydrogen production with high yield is expected to be done at a lower temperature than that of conventional steam reforming.

Titanium absorbs up to two atoms hydrogen per atom titanium, forming dihydrides $\mathrm{TiH}_{2}$ with face-centered cubic structure, sp.gr. Fm3m where hydrogen occupies the tetrahedral sites. At low temperature, below about 310 $\mathrm{K}$ [4], the dihydride transforms to a tetragonal type e hydride sp.gr. I $4 / \mathrm{mmm}$. Several works have been done on phase transformation of titanium. At the end of $50 \mathrm{~s}$, Haag \& Shipko [5] showed through a pressure-compositiontemperature (PCT) experiment that titanium has two equilibrium plateau pressure related to the transformation of $\alpha$-Ti(HCP) to $\beta$-TiHx (BCC), and the $\beta$-TiHx to $\delta-\mathrm{TiH}_{2}(\mathrm{FCC})$. Recently, the most studies focused on kinetics observation by thermal or spectroscopy methods, for example in [6,7]. Kenedy \& Lopez [8] observed that titanium dihydrides desorbed hydrogen in two steps. Bossle et. al. [9] using interrupted TPD methods observed 4 peaks during the dehydrogenation of $\mathrm{TiH}_{2}$. Also, Yang et al. [10] showed 4 peaks related to the hydrogen desorption by using a TPD measurements, with important features that maximum peak was is the third peak. From literature observation, one can see that the literature on titanium hydride dehydrogenation has been scattered. In addition, a study on the reversibility aspect of titanium powder dehydrogenation and hydrogenation in isothermal condition have not been done in the past.

In the present study, the $\mathrm{TiH}_{2}$ dehydrogenation is studied non-isothermally using thermal desorption spectroscopy (TDS). Since the goal of the study was to use metal hydrides for an isothermal condition, the hydrogenation in a gaseous flow at isothermal condition was also investigated.

\section{Materials and Methods}

\subsection{Titanium hydride}

Titanium hydrides powder were prepared by hydrogenation of a $2 \mathrm{~mm}$ foils from SigmaAldrich with purity of $99.2 \%$ metal basis. The chips were cut from foils with weight about 3 grams and placed in an autoclave. The sample inside the autoclave was activated by heating the sample up to $800{ }^{\circ} \mathrm{C}$ in a vacuum, and 32 bar of hydrogen was introduced about $400{ }^{\circ} \mathrm{C}$, and the sample was cooled to room temperature. Afterward, two cycles of hydrogen desorption and absorption up to $850{ }^{\circ} \mathrm{C}$ were done. Ti- tanium sample absorbed 3.83 wt.\% $\quad \mathrm{H}$ $(\mathrm{H} / \mathrm{Ti}=1.91)$ at the end of activation and hydrogenation treatment. The sample was in the form of powder in a micron size ranges. A Jeol JEM 2010 Transmission Electron Microscope (TEM) was used to characterize the micromorphology of the sample.

\subsection{Temperature programmed desorption}

Study on the hydrogen absorption and desorption in gaseous flow were performed in a Temperature-Programmed Desorption (TPD) apparatus. A Thermostar mass spectrometer (MS) from Pfeiffer Vacuum GmbH was connected to the TPD rig. The MS was calibrated to determine concentrations of $\mathrm{H}_{2}$ and $\mathrm{Ar}$ in the outgoing gaseous flow from the reactor. The hydrogen concentrations vs. time data profiles were plotted, and the amount of hydrogen absorbed and desorbed during the measurements were calculated. Hydrogen gas absorption and desorption experiments were performed at gaseous flow rates of 50 and $300 \mathrm{~mL} / \mathrm{min}$ at a heating rate of $3 \mathrm{~K} / \mathrm{min}, 5 \mathrm{~K} / \mathrm{min}$, and 10 $\mathrm{K} / \mathrm{min}$.

\subsection{Temperature desorption spectroscopy}

Dehydrogenation of titanium hydrides were performed either in a vacuum $\left(\sim 1 \times 10^{-5} \mathrm{mbar}\right)$ using thermal desorption spectroscopy technique or in the gas flow in the TPD setup. During the TDS experiment in a vacuum and hydrogenation in the TPD, the in situ hydrogenation were possible so that the effect of gas contamination from an ambient atmosphere can be controlled. The TDS and the TPD studies were done at the heating rate of 3,5 , and $10 \mathrm{~K} / \mathrm{min}$; the temperature ranges were from room temperature (RT) to up to $850^{\circ} \mathrm{C}$.

\section{Results and Discussion}

\subsection{Hydrides morphology and microstruc- ture}

Morphology of the hydride powder was examined by using the TEM. As can be seen in Figure 1, the titanium hydride powder particles were in micron size ranges. The magnification of some area from Figure 1a can be seen in Figure $1 \mathrm{~b}$ where a micron size hydride consisted of a sub-micron grain. At room temperature in the TEM chamber, the hydride particles were observed as an FCC $d$-hydrides as confirmed by diffraction image and analysis as shown in Figure 1c. 


\subsection{Thermal desorption studies in vacuum}

The hydride was synthesized in situ in a TDS autoclave to avoid oxidation by the atmospheric gases. TDS experiments in a vacuum $\left(\sim 1 \times 10^{-5}\right.$ mbar $)$ were performed at different heating rates at $3-10 \mathrm{~K} / \mathrm{s}$ from room temperature to $850{ }^{\circ} \mathrm{C}$ as shown in Figure 2a. In general, the dehydrogenation was started with hydrogen desorption at low temperature about 100-200 ${ }^{\circ} \mathrm{C}$, except for the oxidized sample (sample labeled with $10 \mathrm{~K} / \mathrm{min}-\mathrm{B}$ ) that started to desorb hydrogen at moderate temperature. Peak temperature is shown in the desorption curves which depended on the heating rate, for $5 \mathrm{~K} / \mathrm{min}$ the peak temperature was $450{ }^{\circ} \mathrm{C}$ and higher for the faster heating rate. The hydrogen desorption was lasted up to a high temperature of about $800{ }^{\circ} \mathrm{C}$.

Using a deconvolution procedure [11], the TDS spectra can be fitted with 4 curves which mean that dehydrogenation of $\mathrm{TiH}_{2}$ consisted of 4 steps. An example of TDS curve deconvolution is shown in Figure $2 \mathrm{~b}$ for $5 \mathrm{~K} / \mathrm{min}$ heating rate. The amount of hydrogen desorption at each step can be estimated from the area under the curve about the overall amount of desorbed hydrogen. By this method, the amount of hydrogen shown by curve 1 is $0.50 \mathrm{H} / \mathrm{M}$. At moderate temperature, the hydrogen desorption is from the curve 2 which is $0.82 \mathrm{H} / \mathrm{M}$ hydrogen desorbed. This hydrogen desorption must be the hydrogen desorption from the $\delta \rightarrow \beta$ transformation, since it is the faster hydrogenation rate of desorbed hydrogen. The next hydrogen desorption is shown by the third peak of hydrogen desorption which is started at the middle of the

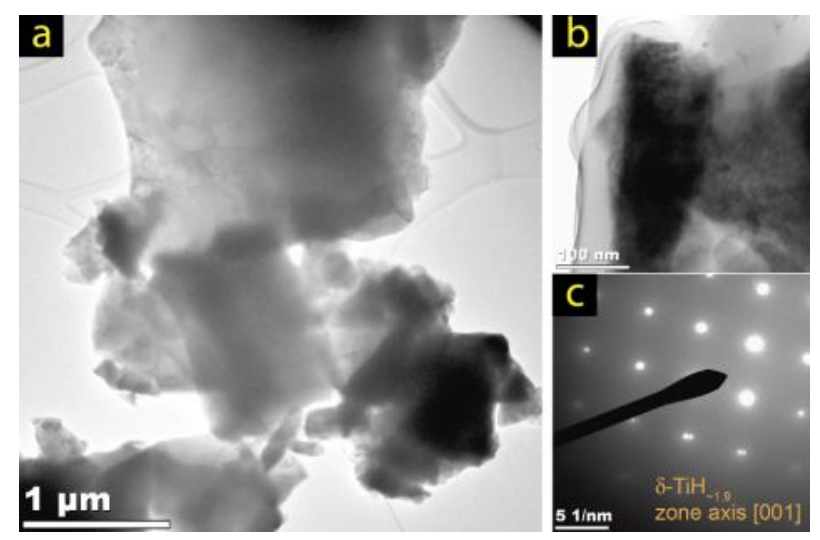

Figure 1. Micro-morphology of the hydrides after re-hydrogenation; (a) The scale of the hydrides particle size in the micron ranges, (b) Magnification of the hydrides particle identified as $\delta$ hydride, (c) TEM image of the diffraction patterns. curve 2, which means that the hydrogen desorption is correlated with hydrogen desorption from the $\beta$ hydrides which is $0.48 \mathrm{H} / \mathrm{M}$. At high temperature, small amounts of hydrogen desorbed was observed, i.e. $0.11 \mathrm{H} / \mathrm{M}$, therefore it must be correlated with hydrogen desorption from the hexagonal a phase. Therefore, from these TD spectra, dehydrogenation of the titanium hydride is composed of 4 steps correlated with 4 peaks in the TD spectra, i.e. $\delta \mathrm{TiH}_{1.91} \rightarrow$ $\delta \mathrm{TiH}_{1.41} \rightarrow \beta \mathrm{TiH}_{0.59} \rightarrow \alpha \mathrm{TiH}_{0.11}$. Yang et al. [10] also reported that the hydrogen desorption consisted of 4 steps. However, there is a substantially different with our work that is in the present work; maximum peak is correlated with phase transformation of the $\delta \rightarrow \beta$ hydrides. A TDS experiment was also performed for a sample after exposed in air for 24 hours as shown in Figure 2a. The onset of hydrogen desorption was higher than that of the un-exposed sample, and the TDS curve for the exposed sample is composed of mainly three distinct peaks.
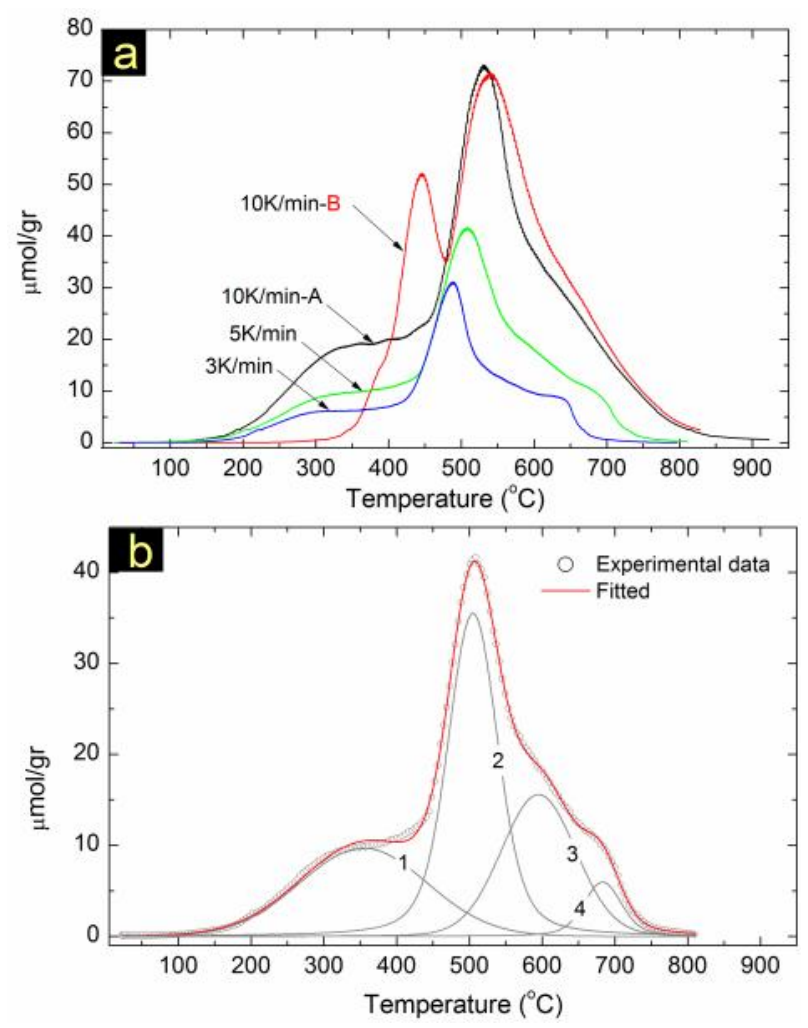

Figure 2. Thermal desorption spectra from titanium dihydrides: (a) TDS of insitu rehydrogenated samples with different heating rate, except for sample $10 \mathrm{~K} / \mathrm{min}-\mathrm{B}$ which was exposed to air for 24 hours before dehydrogenation experiment, (b) Deconvolution of TDS spectra of $5 \mathrm{~K} / \mathrm{min}$ indicates that hydrogen desorption of $\mathrm{TiH}_{1.9}$ was composed of 4 curves. 
Even though, the dehydrogenation path was the transformation of $\delta \rightarrow \beta \rightarrow \alpha$, overlapping's of two dehydrogenation events were observed as shown in the deconvoluted curves. It can also be observed that when the heating rate increased, the possibility of the formation was smaller. The previous investigation on the phase structural changes [10] showed that during non-isothermal hydrogen desorption of $\mathrm{TiH}_{2}$ in helium flow, the dehydrogenation path of $\mathrm{TiH}_{2}$ was $\varepsilon \rightarrow \delta \rightarrow \beta+\alpha \rightarrow \alpha$. This is in agreement with the dehydrogenation path if it is plotted in the phase diagram Ti-H which is shown in Figure 3. The activation energy for hydrogen desorption in each step of dehydrogenation was calculated by using the Kissinger analysis. Different heating rates were applied for the dehydrogenation, and the activation energy was determined using expression in Equation (1):

$$
\ln \frac{\beta_{i}}{T_{j i}^{2}}=A(j)-\frac{E_{j}}{R T_{j i}}
$$

where $\beta$ is the heating rate is applied $(\mathrm{K} / \mathrm{min})$, $T$ is the peak temperature (K), $A$ is the preexponential factor, and $E$ is the activation energy $(\mathrm{kJ} / \mathrm{mol})$. The index $i$ is the for different heating rate and $j$ is index for the peak temperatures. So the dehydrogenation curve was deconvoluted, and each peak at each heating rate was used to determine the activation energy. Table 1 shows the list of activation energy for each step which is related to the activation energy of decomposition of hydride phase. The activation energy of transformation of $\delta$ to $\beta$ is about $134 \mathrm{~kJ} / \mathrm{mol}$ which is in agreement with

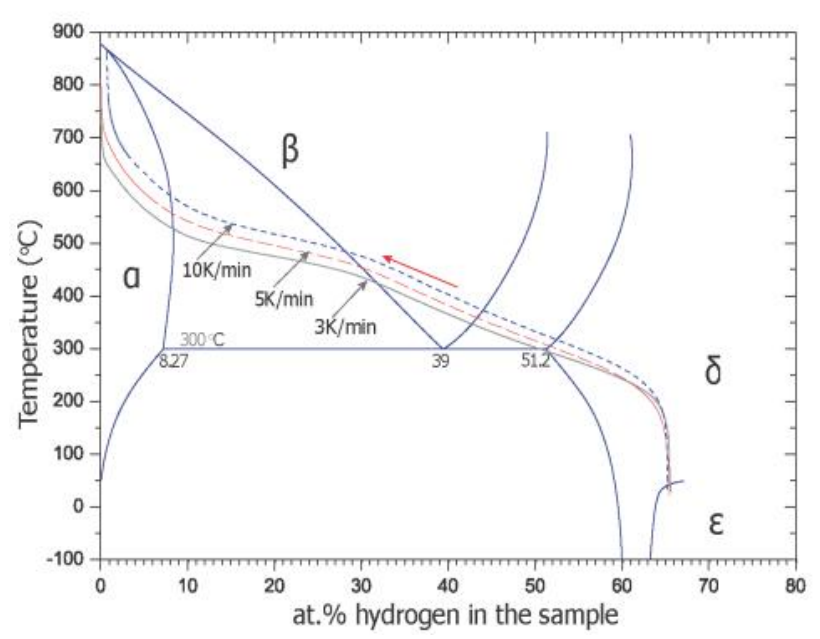

Figure 3. Plot of dehydrogenation paths in the Ti-H phase diagrams showing the possible path for dehydrogenation process in vacuum and in the previous investigation by Liu who did model $\mathrm{TiH}_{2}$ dehydrogenation [6].

\subsection{Hydrogen desorption and absorption in gaseous flow}

Hydrogen desorption in a gaseous flow was performed in TPR set up in argon flow of 300 $\mathrm{mL} / \mathrm{min}$ and a heating rate of $3 \mathrm{~K} / \mathrm{min}$ to 760 ${ }^{\circ} \mathrm{C}$. Hydrogen desorption spectra of the initial sample, $\mathrm{TiH}_{1.91}$ powder, can be seen in Figure 4 in which three distinct peaks were observed. After the $1^{\text {st }}$ dehydrogenation, the sample was re-hydrogenated by allowing $25 \% \mathrm{H}_{2}$ in the argon flow at 1 bar. Then, the in-situ hydrogenated sample was heated again to do the $2^{\text {nd }}$ dehydrogenation in a similar heating rate to the $1^{\text {st }}$ dehydrogenation. It can be seen in Figure 4 that the non-perfect peak of the $1^{\text {st }}$ dehydrogenation is observed. This result is in agreement with a previous observation [13] but different with a recent investigation [14], where a small peak as supposed to be from the phase was not observed in our case.

\subsection{Isothermal hydrogen absorption}

To further study the behavior of titanium during hydrogenation and dehydrogenation, experiments were done in a TPR setup using a quart U-shape sample cell. The dehydrogenation was done in argon flow of $50 \mathrm{~mL} / \mathrm{min}$ at 1 bar total pressure at $5 \mathrm{~K} / \mathrm{min}$, and the hydrogenation was done in $50 \mathrm{~mL} / \mathrm{min}$ of Ar+15\% $\mathrm{H}_{2}$. The temperature desorption spectra of the initial powder partially hydrogenated sample are shown in Figure 5b. It can be observed that during dehydrogenation of the initial sample

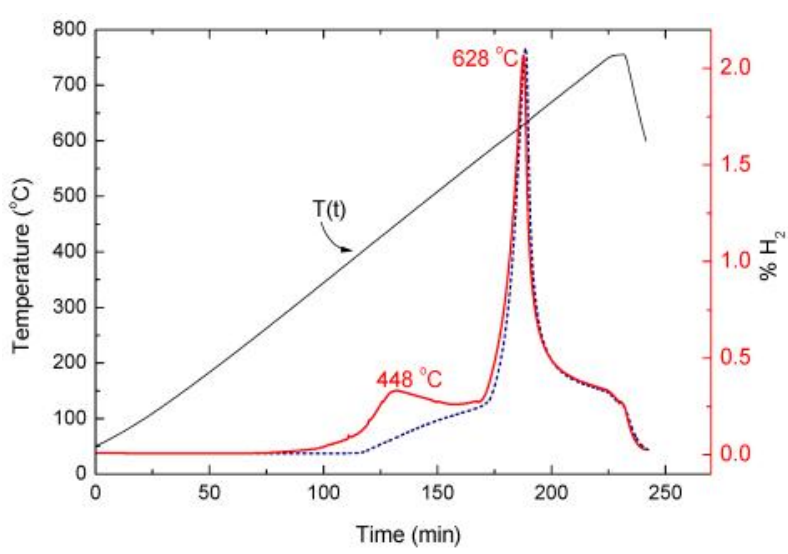

Figure 4. Hydrogen desorption spectra obtained using TPD using tube type sample cell. Sample was rehydrogenated in situ prior to $2^{\text {nd }}$ dehydrogenation. There was an absent of the $1^{\text {st }}$ peak during $2^{\text {nd }}$ dehydrogenation. Dehydrogenation was done at $300 \mathrm{~mL} / \mathrm{min}$. 
containing 3.83 wt.\%, i.e. dehyd 1 , the dehydrogenation was composed of only two peaks, the main peak at $552{ }^{\circ} \mathrm{C}$ and the second peak at $665^{\circ} \mathrm{C}$, which means that not all peaks related to the titanium hydride as TDS curves shown were not well resolved. However, small asymmetry of the $1^{\text {st }}$ peak is an indication that this curve was actually composed of three peaks. The dead volume in the cell was probably the reason for this behavior. Dehydrogenation curves of partly hydrogenated samples are shown in Figure 5b. Calculations from the integration of the curve show that amount of hydrogen desorbed from the $2^{\text {nd }}$ dehydrogenation and $3^{\text {rd }}$ dehydrogenation was 2.70 and $2.57 \mathrm{wt}$. $\%$ respectively. It can be seen that the dehydrogenation curves is composed of 2 peaks were most likely correlated with hydrogen desorption from $\beta$ phase hydride, and from the phase for the second peak.

The hydride formation and the kinetics depend on the initial hydrogen content in the sample prior to hydrogenation and the temperature. The hydrogen absorption curves of the samples at different isothermal temperatures is shown in Figure 5a. It can be seen that at $475{ }^{\circ} \mathrm{C}$, hydrogen absorption approximately follow a linear relationship with time. This indicates that hydrogenation was controlled by $\mathrm{H}_{2}$ chemisorption at the surface of the particles. When hydrogenation was done at $525{ }^{\circ} \mathrm{C}$, hydrogenation followed a sigmoid curve. This observation is in qualitative agreement with a previous investigation [15]. The amount of hydrogen absorbed was 3 wt.\% when hydrogenation was done at $525^{\circ} \mathrm{C}$, and it was $2.8 \mathrm{wt} . \%$ at $475{ }^{\circ} \mathrm{C}$ for 90 minutes hydrogenation. The different amount of hydrogen between the absorption and desorption is a result of experimental procedure where a switch of the gas flow was done at the hydrogenation temperature. Thus, some of the hydrogen must be desorbed during gas switching. From these results, the correlation between the hydrogen absorption and desorption can be made. At the absorption temperatures, the $\beta$ was transformed to low stoichiometric $\delta$-hydride. Then the hydrogen desorption was come from the transformation during $\delta$ to $\beta$, a similar process as shown by TDS, and this followed by hydrogen desorption from the $\beta$ hydride up to $850{ }^{\circ} \mathrm{C}$. The dehydrogenation process during nonisothermal hydrogen desorption can be written as follows:
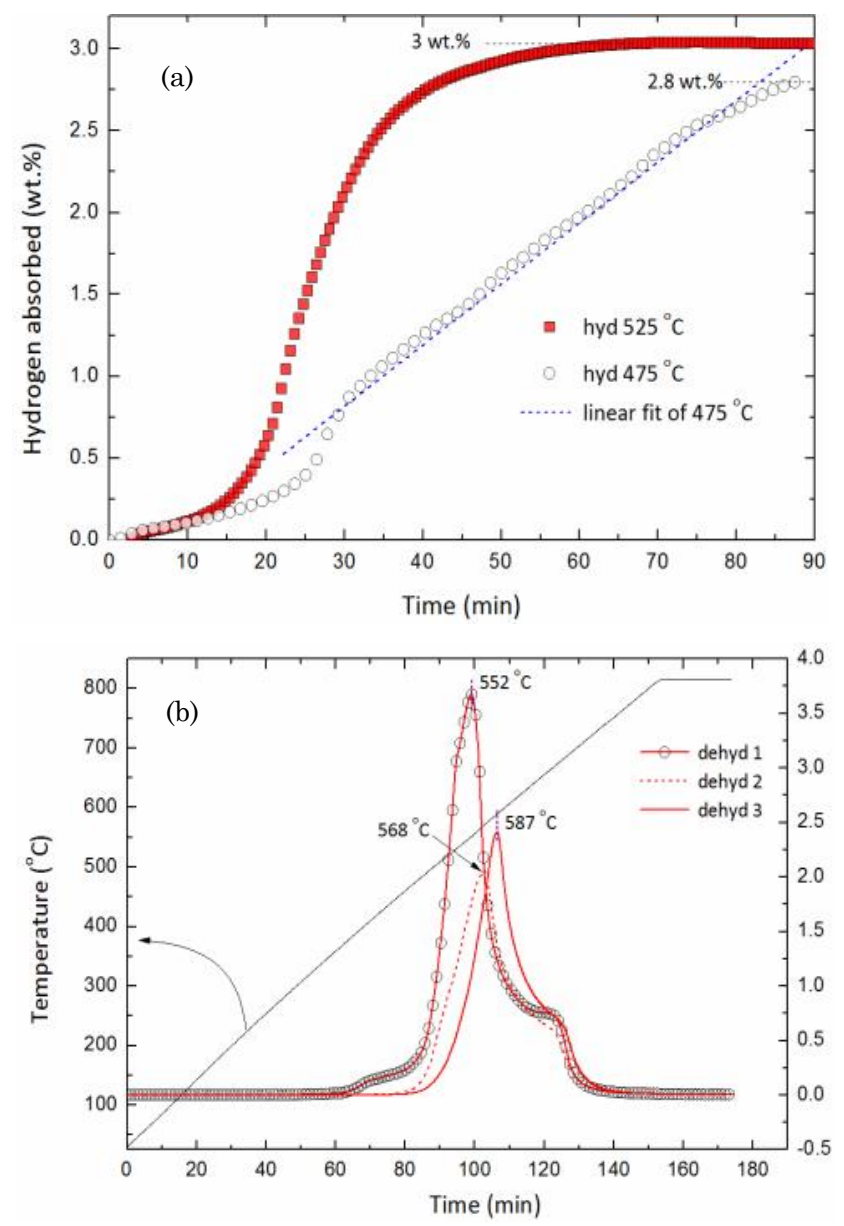

Figure 5. Hydrogenation (a) and dehydrogenation (b) of the titanium and titanium hydride powder in TPR using U-shape quartz cell. In Figure $3 b$ dehyd 1 was dehydrogenation of initial dihydride sample, dehyd 2 was dehydrogenation of sample hydrogenated at $476{ }^{\circ} \mathrm{C}$, and the dehyd 3 was dehydrogenated of the sample hydrogenated at $525{ }^{\circ} \mathrm{C}$. Hydrogenation and dehydrogenation was done at $50 \mathrm{~mL} / \mathrm{min}$ gas flow.

Table 1. Possible hydride transformation during vacuum dehydrogenation as related to the TDS peak temperature and their apparent activation energy for dehydrogenation

\begin{tabular}{ccccc}
\hline Curve & Fitted TDS peak $\left({ }^{\circ} \mathrm{C}\right)$ & $\mathrm{H}$ desorbed $(\mathrm{H} / \mathrm{M})$ & $\mathrm{E}_{\mathrm{AA}}(\mathrm{kJ} / \mathrm{mol})$ & Related hydride phase \\
\hline 1 & 354 & 0.50 & $134 \pm 3.5$ & $\delta$ - $\mathrm{TiH}_{1.91}$ \\
2 & 504 & 0.82 & $127 \pm 8.9$ & $\delta-\mathrm{TiH}_{1.41}$ \\
3 & 594 & 0.47 & $134 \pm 0.5$ & $\beta-\mathrm{TiH}_{0.47}$ \\
4 & 683 & 0.11 & $82 \pm 15$ & $\alpha-\mathrm{TiH}_{0.11}$ \\
\hline
\end{tabular}


$\delta \mathrm{TiH}_{1.9} \rightarrow \delta \mathrm{TiH}_{1.9-\mathrm{x}} \rightarrow \beta \mathrm{TiH}_{\mathrm{x}}$ either in gas flow or vacuum.

\section{Conclusions}

The present work shows that the dehydrogenation steps of $\mathrm{TiH}_{2}$ both in a vacuum and gaseous flow is $\delta-\mathrm{TiH}_{1.9} \rightarrow \beta-\mathrm{TiH}_{1.9-\mathrm{x}} \rightarrow \alpha-\mathrm{TiH}_{\mathrm{x}}$ even though co-existences of these phases were observed during the dehydrogenation process. The number of peaks in the dehydrogenation spectra correlated with surface condition and completeness of the pre-hydrogenation process. Mechanism of hydrogenation in gaseous flow was highly dependent on the temperature. The hydrogen absorption kinetics at queasy equilibrium temperature indicated that at temperature of $475{ }^{\circ} \mathrm{C}$, the hydrogenation was controlled by chemisorption of hydrogen which is surface controlled process. Hydrogen absorption and desorption experiments revealed that during hydrogenation/dehydrogenation in a gas flow a reversible transformation of $\beta-\mathrm{TiH}_{0.59} \Leftrightarrow$ $\delta$ - $\mathrm{TiH}_{1.41}$ was observed with reversible capacity of $2 \mathrm{wt} . \% \mathrm{H}$ at working temperature of 500-760 ${ }^{\circ} \mathrm{C}$. The activation energy for $\delta-\mathrm{TiH}_{1.41} \rightarrow$ $\beta-\mathrm{TiH}_{0.59}$ transformation is $127 \mathrm{~kJ} / \mathrm{mol}$.

\section{Acknowledgement}

The authors thank J.P. Maehlen for his assistance during the hydrogen absorption and desorption experiment.

\section{References}

[1] Lee, H.-H., Lee, K.-Y., Lee, J.-Y. (1996). The Ti-Based Metal Hydride Electrode for Ni-MH Rechargeable Batteries. Journal of Alloys and Compounds, 239(1): 63-70.

[2] Kawahito, K., Zeng, L., Ichikawa, T., Miyaoka, H., Kojima, Y. (2016). Electrochemical Performance of Titanium Hydride for BulkType All-Solid-State Lithium-Ion Batteries. Materials Transactions. 57(5): 755-757.

[3] Aymard, L., Oumellal, Y., Bonnet, J.-P. (2015). Metal Hydrides: An Innovative and Challenging Conversion Reaction Anode for Lithium-Ion Batteries. Beilstein Journal of Nanotechnology, 6(1): 1821-1839.

[4] Yakel, H. (1958). Thermocrystallography of Higher Hydrides of Titanium and Zirconium. Acta Crystallographica, 11(1): 46-51.
[5] Haag, R., Shipko, F. (1956). The TitaniumHydrogen System. Journal of the American Chemical Society, 78(20): 5155-5159.

[6] Liu, H., He, P., Feng, J.C., Cao, J. (2009). Kinetic Study on Nonisothermal Dehydrogenation of $\mathrm{TiH}_{2}$ Powders. International Journal of Hydrogen Energy, 34(7): 3018-3025.

[7] Borchers, C., Khomenko, T.I., Leonov, A.V., Morozova, O.S. (2009). Interrupted Thermal Desorption of $\mathrm{TiH}_{2}$. Thermochimica Acta, 493(1-2): 80-84.

[8] Kennedy, A., Lopez, V. (2003). The Decomposition Behavior of as-Received and Oxidized $\mathrm{TiH}_{2}$ Foaming-Agent Powder. Materials Science and Engineering: A, 357(1): 258-263.

[9] Bhosle, V., Baburaj, E.G., Miranova, M., Salama, K. (2003). Dehydrogenation of $\mathrm{TiH}_{2}$. Materials Science and Engineering: A, 356(12): 190-199.

[10] Yang, D., Hur, B., He, D., Yang, S. (2007). Effect of Decomposition Properties of Titanium Hydride on the Foaming Process and Pore Structures of Al Alloy Melt Foam. Materials Science and Engineering: A, 445: 415-426.

[11] Suwarno, S., Solberg, J.K., Mæhlen, J.P., Denys, R.V., Krogh, B., Ochoa-Fernández, E. et al. (2013). Non-isothermal kinetics and in situ SR XRD studies of hydrogen desorption from dihydrides of binary Ti-V alloys. International Journal of Hydrogen Energy, 38: 14704-14714

[12] Kobzenko, G., Kobzenko, A., Chubenko, M., Pet'kov, V., Polenur, A. (1995). Crystal Structure Change of Titanium Hydride Desorption Products in Helium. International Journal of Hydrogen Energy, 20(5): 383-386.

[13] Matijasevic-Lux, B., Banhart, J., Fiechter, S., Görke, O., Wanderka, N. (2006). Modification of Titanium Hydride for Improved Aluminium Foam Manufacture. Acta Materialia, 54(7): 1887-1900.

[14] Jiménez, C., Garcia-Moreno, F., Pfretzschner, B., Klaus, M., Wollgarten, M., Zizak, I., Schumacher, G., Tovar, M., Banhart, J. (2011). Decomposition of $\mathrm{TiH} 2$ Studied in Situ by Synchrotron X-Ray and Neutron Diffraction. Acta Materialia, 59(16): 6318-6330.

[15] Hirooka, Y., Miyake, M., Sano, T. (1981). A Study of Hydrogen Absorption and Desorption by Titanium. Journal of Nuclear Materials, 96(3): 227-232.

Selected and Revised Papers from The $2^{\text {nd }}$ International Seminar on Chemistry (ISoC 2016) (Surabaya, 26-27 July 2016) (http://chem.its.ac.id/isoc-2016/) after Peer-reviewed by Scientific Committee of ISoC 2016 and Peer-Reviewers of BCREC journal 